\title{
STUDY OF THE CRATERS OF THE MOON OBSERVED FROM NATIONAL OBSERVATORY NAGARKOT, NEPAL
}

\author{
P. Parajuli *, P.R. Dhungel*, U. Khanal** and S.R. Shahi*** \\ *St.Xavier's College Maitighar, Kathmandu, Nepal. \\ **Central Department of Physics, Tribhuvan university, Kirtipur, Kathmandu, Nepal. \\ ***B.P. Koirala Memoriala Planetarium, Observataroy and Science Museum Development Board, Singha Dubar, \\ Kathmandu, Nepal.
}

\begin{abstract}
We studied the craters of the satellite Moon using images taken from National Observatory located at Nagarkot, Bhaktapur, Nepal during the period from November 8, 2012 to January 14, 2014. We captured the images of the crater of the Moon using Meade 16-inch LX200GPS Schmidt-Cassegrain telescope. The images were processed in the software ALADIN 2.5. To measure the distance, we drew lines across the craters, and took the lengths of those lines using ALADIN 2.5 software in terms of pixel size. Using the pixel size of the image from the software, we obtained the diameter of the craters under study. This work includes the measured diameters of eight different craters of Moon, and their comparison with the published results. Our findings on the diameter of the craters of moon is in close agreement with the published values.
\end{abstract}

Keywords: Moon; Craters; Schmidt-Cassegrain telescope; FITS images.

\section{INTRODUCTION}

\section{Moon}

Moon is the Earth's only natural satellite and the closest heavenly bodies to the Earth. The Moon's diameter is roughly 2160 miles (3480 kilometers) and it is 81 times smaller in mass than Earth and is about 238,900 miles away from the Earth. The moon phases and the Moon's

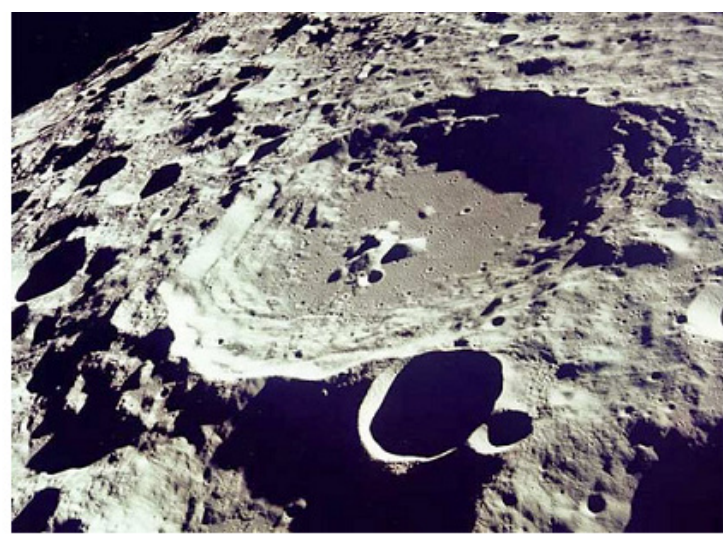

Figure :1.1 Crater 308 on the Moon (Image Courtesy of NASA [1]

orbit are mystery to many. Because it takes 27.3 days both to rotate on its axis and orbit Earth, so the Moon always shows us the same face, it is in a synchronous rotation with the Earth.
The moon is a mysterious heavenly body with characteristics even more mysterious. We all must have noticed the two shades of color in the moon: darker gray, smoother regions with few craters (the Maria); and brighter gray, more rugged regions with many craters (the highlands). Craters, though we may have always heard about it, we may not have given a deep thought about it. [2]

\section{Craters}

The smallest lunar features we can distinguish with the naked eye are about $200 \mathrm{~km}$ across, we see little more than the maria and highlands when we gaze at the moon. Through a telescope, however, we find that the lunar surface is scarred by numerous bowl-shaped craters (after the Greek word for bowl). Most craters formed eons ago as the result of meteoritic impact. Meteoroids generally strike the Moon at speeds of several kilometers per second. At these speed even a small piece of matter carries an enormous amount of energy. So, the impact by a meteoroid causes sudden and tremendous pressures to build up on the lunar surface, heating the normally brittle rock and deforming the ground. The ensuing explosion pushes previously at layers of rock up and out, forming a crater. The vast majority of the moon's craters are formed by the impact of meteoroids, asteroids, and comets. Craters on the moon are named after famous scientists. For example, Copernicus

Author for Correspondence: P. Parajuli, St.Xavier's College Maitighar, Kathmandu, Nepal. E-mail: pratikshya.parajuli@gmail.com. 
Crater is named after Nicholas Copernicus, a Polish astronomer who realized in the 1500's that the planets move about the sun. Archimedes Crater is named for the Greek mathematician Archimedes, who made many mathematical discoveries in the 200 B.C.

The shape of craters varies with their size. Small craters with diameters of less than 6 miles (10 kilometers) have relatively simple bowl shapes. Slightly larger craters cannot maintain a bowl shape because the crater wall is too steep. Material falls inward from the wall to the floor. As a result, the walls become scalloped and the floor becomes flat.

Crater rays are light, wispy deposits of powder that can extend thousands of miles or kilometers from the crater. Rays slowly vanish as micrometeoroid bombardment mixes the powder into the upper surface layer. Thus, craters that still have visible rays must be among the youngest craters on the moon.

Lunar craters come in all sizes, rejecting the range in sizes of the impactors that create them. The largest craters are hundreds of kilometers in diameter, the smallest microscopic. Because the moon has no protective atmosphere, even tiny interplanetary fragments can reach the lunar surface unimpeded, resulting the formation of a crater [3].

\section{OBSERVATION}

\section{National Observatory}

Government of Nepal has established B.P. Koirala Memorial planetarium, Observatory and Science Museum Development Board in Nepal in 1992 in order to conduct research activities in the area of Astronomy, Astrophysics and Cosmology.

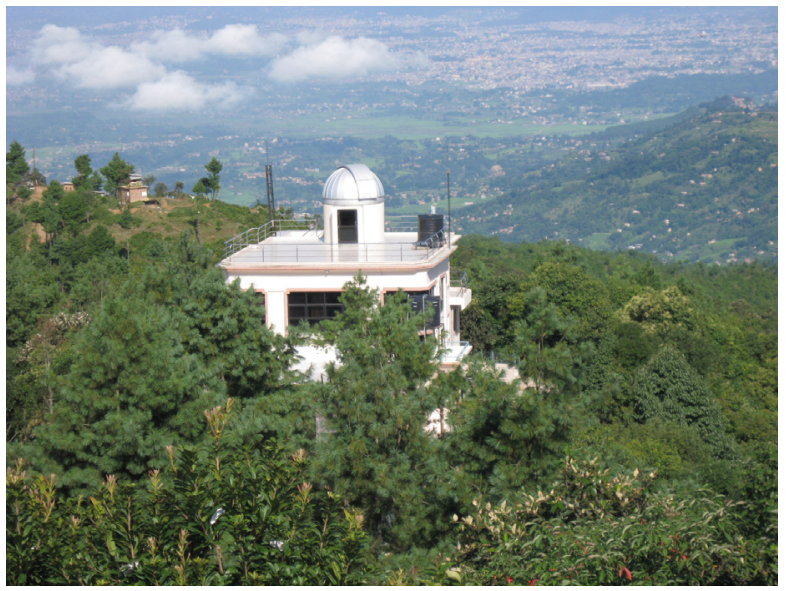

Figure:1.2 National Observatory, Nagarkot.

National Observatory is one of the leading organizations in the field of research in Astronomy and Astrophysics. It has been encouraging the students in this arena by providing fellowship and giving them an opportunity of observing the celestial bodies through the apparatus they have since its birth. It is located in the very peaceful environment at Nagarkot at a Latitude of $27^{\circ} 42^{\prime} 06^{\prime \prime} \mathrm{N}$ and at Longitude of $85^{\circ} 31^{\prime} 00 \mathrm{E}$. This opportunity is a great boon for us in our future research in Astronomy to the Nepali students. This observatory constitutes a two-storey building in which the 16-inch LX200GPS SchmidtCassegrain telescope has been installed. In addition there is a guest house that offers all the facilities to the observers. The first observing was done on November 11, 2012. During the observation period at that time, the JPEG and Fits images of different celestial objects like our Moon, Stars,Jupiter were taken.

The second observation was conducted during August, 2013 and November2013. The FITS images of the craters of the moon, ring of Jupiter were taken during that time. The last observation was conducted in January 14, 2014. At that period, many images of the moon and craters were captured.

\section{MATERIALS AND METHODS}

\section{Observational Work}

During the field time, various properties of the lunar craters seen while observing the moon need to be observed by the aid of the local apparatus available in the Observatory, taking as much benefit as possible. Basically, small scale telescope is widely used in this research. For this Meade 16" LX200GPS SchmidtCassegrain telescope is used. Primary and secondary data was also collected. Then the mathematical tools and simulation programs were used to analyze the data. Different graphs and elaborated drawings were used to express the result obtained during the study and simulation. Finally the result was assembled in a paper. Different programs like Matlab, and Origin were used for analyzing and plotting / presenting the data obtained. The Fits image of the Craters were processed in the software ALADIN 2.5, FITSVIEW and AUTOSTAR.

Size or diameter of the craters were calculated using ALADIN V2.5. The official size of the craters were obtained along with their latitude and longitude and compared with our calculated size. Then, we plotted the graph of difference in size versus the published size using ORIGIN 5.0.

\section{Digital imaging of the Moon}

The digital imaging of the moon was done by using a permanently mounted 16-Inch f/10 Schmidt Cassegrain Telescope. Two days before the full moon, images of the lunar craters were captured and it was done on 14 January, 2014 around 8 o'clock. The time and date were recorded and is now used to determine the correct distance and the angle of the sun to the lunar surface. 


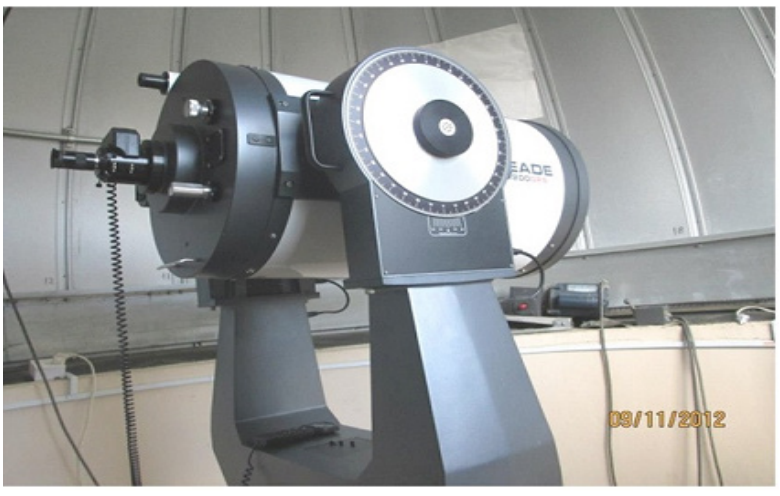

Figure: 1.3 16- Inch LX200GPS Schmidt-Cassegrain Telescope [4]

The identification of the lunar craters however did not occur naturally. By going through the "The Full Moon Atlas" [5], identification was done. The following are some of the craters that we did identify in our research with the calculation of their diameter by using the following formula.

The image scale per pixel in arc seconds was determined and then converted to degrees. Corrections factor for foreshortening due to lunar curvature known as tilt correction factor (tcf) is given by:

Tilt correction factor (tcf ) $=1 / \cos$ (latitude) $\times$ $\cos$ (longitude)

The Earth-Moon distance at 14 January 2014 was, D = $400,269 \mathrm{~km}$, so the Linear distance on Moon covered by one pixel (ldpixel) is:

ld pixel $=\mathrm{D}[\mathrm{km}] \times \tan \left(7.78 \times 10^{-5}\right.$ degrees $)$

ldpixel $=400.269 * \tan \left(7.78 \times 10^{-5}\right.$ degrees $)=0.5435 \mathrm{~km}$

With ALADIN 2.5, we can directly get the distance between two points which is $\mathrm{Z}$.

Uncorrected length of crater (ulpixel) $=\mathrm{Z}$

Corrected length of crater; $(\mathrm{cl})=$ ulpixel $\times \operatorname{tcf}$

Length of crater $(\mathrm{L}(\mathrm{km}))=\mathrm{cl} \times \mathrm{ld} \times$ ulpixel [6]

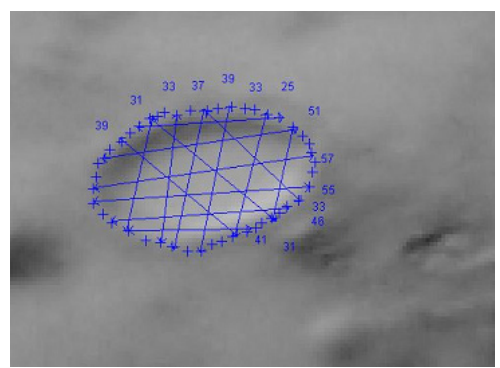

A.1 Billy [13:8 S, 50:1W] Crater (45 km)

Tilt Correction factor $=1 / \cos (13.8) \times \cos (50.1)=$ 1.6054 Uncorrected length of crater obtained from ALADIN 2.5 $=39.266$ So, the diameter of crater Billy= $1.6054 \times 39.2666 \times 0.5435=34.2615 \mathrm{~km}$.

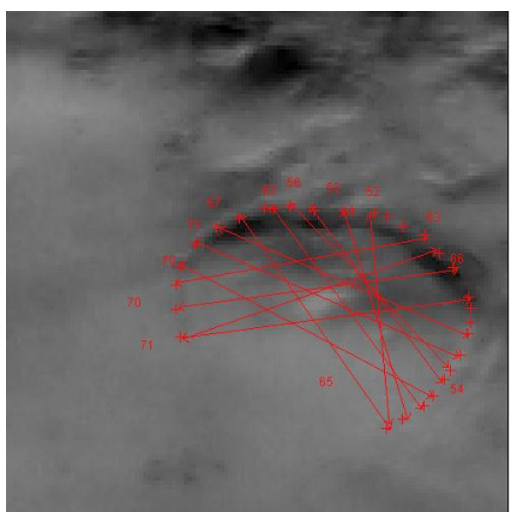

A.2 Dopplemayer [28.5S, 41.4N] Crater $(64 \mathrm{~km})$

Tilt Correction factor tcf $=1 / \cos (28.5) \times \cos (40.4)=$ 1:5170

Uncorrected length of crater obtained from Aladin 2.5 $($ ulpixel $)=63.7692$

Length of crater $=1.5170 \times 63.7692 \times 0.5435=52.5770$

So, the calculated diameter of Dopplemayer crater is $52.5770 \mathrm{~km}$.

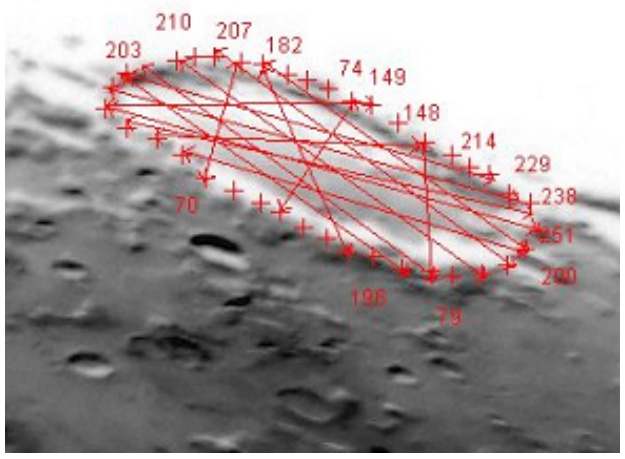

A.3 Schickard [ 44.4S, 54.6W ] Crater ( 227km)

Tilt Correction factor tcf $=1 / \cos (44: 4) \times \cos (54: 6)=$ 2:380

Uncorrected length of crater obtained from Aladin 2.5 $($ ulpixel $)=175.3502$

Length of crater $=2.380 \times 175.3502 \times 0.5435=226.8207$

So, the calculated diameter of Schickard crater is $226.8207 \mathrm{~km}$.

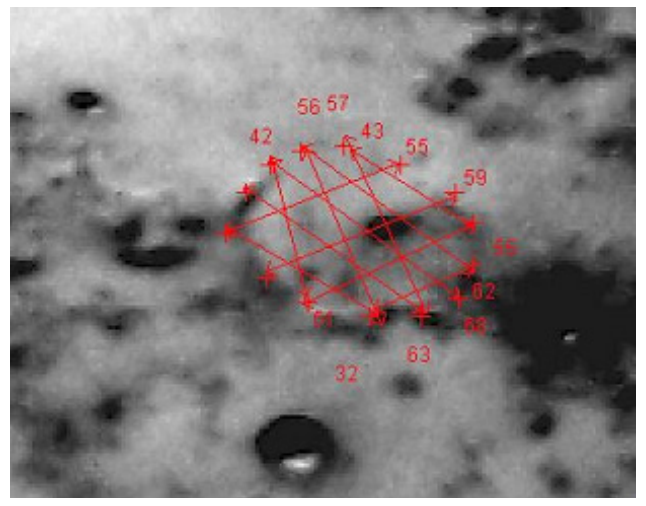

A.4 Hippalus [ 24.8S, 30.2W ] Crater ( 58km) 
Tilt Correction factor tcf $=1 / \cos (24.8) \times \cos (30.2)=$ 1.2745

Uncorrected length of crater obtained from Aladin 2.5 $($ ulpixel $)=53.5833$

Length of crater $=1: 2745 \times 53: 5833 \times 0: 5435=37.1167$

So, the calculated diameter of Hippalus crater is 37.1167 $\mathrm{km}$.

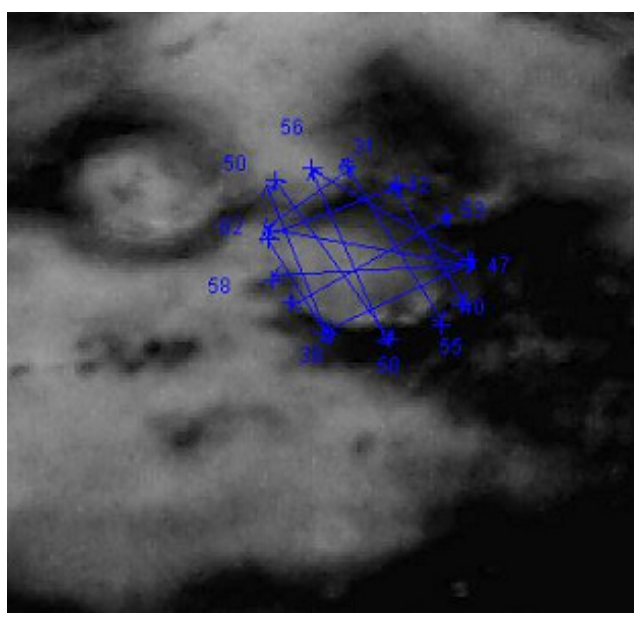

A.5 Mercator [29.3S, 26.1W] Crater $(47 \mathrm{~km})$

Tilt Correction factor tcf $=1 / \cos (29.3) \times \cos (26.1)=$ 1.2770

Uncorrected length of crater obtained from Aladin 2.5 $($ ulpixel $)=49.1$

Length of crater $=1: 2770 \times 49: 1667 \times 0: 5435=34.1241$

So, the calculated diameter of Mercator crater is 34.1241 $\mathrm{km}$.

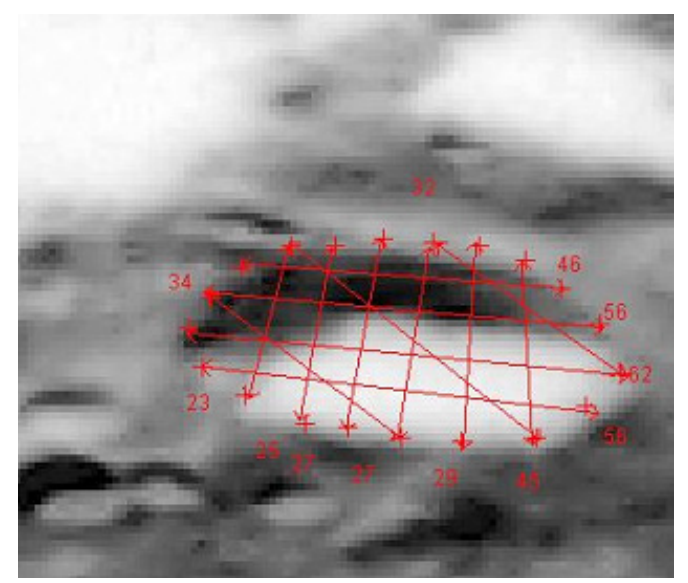

A.6 Palmieri [ 28.6S, 47.7W ] Crater (40km)

Tilt Correction factor tcf $=1 / \cos (28.6) \times \cos (47.7)=$ 1.6923

Uncorrected length of crater obtained from Aladin 2.5 $($ ulpixel $)=37.6153$

Length of crater $=1.6923 \times 37: 6153 \times 0: 5435=34.5972$

So, the calculated diameter of Palmieri crater is 34.5972 $\mathrm{km}$.

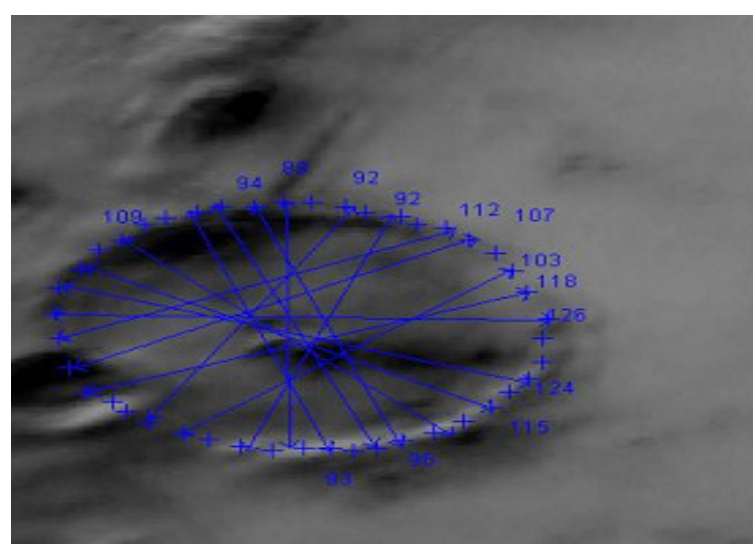

A.7 Gassendi [17.5S,39.9W] Crater ( 110km)

Tilt Correction factor tcf $=1 / \cos (17.5) \times \cos (39.9)=$ $1: 3667$

Uncorrected length of crater obtained from Aladin 2.5 $($ ulpixel $)=105.2857$

Length of crater $=1: 3667 \times 105: 2857 \times 0: 5435=$ 78.2061

So, the calculated diameter of Gassendi crater is 78.2061 $\mathrm{km}$

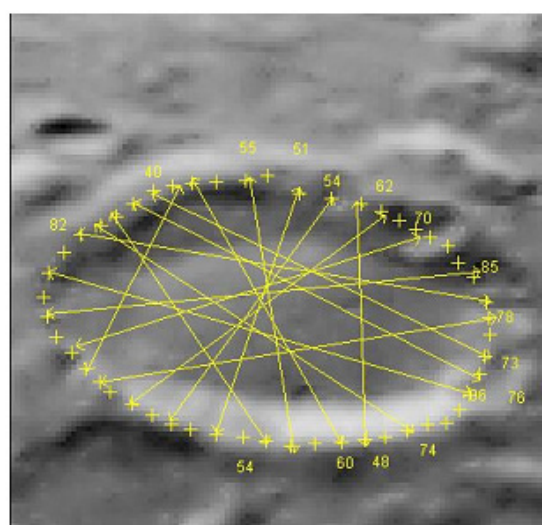

A.8 Mersenius [ 21.5S, 49.2W ] Crater ( $84 \mathrm{~km})$

Tilt Correction factor tcf $=1 / \cos (21.5) \times \cos (49.2)=$ 1.6447

Uncorrected length of crater obtained from Aladin 2.5 (ulpixel) $=70.5$

Length of crater $=1.6447 \times 70.5 \times 0.5435=63.0196$

So, the calculated diameter of Mersenius crater is $63.0196 \mathrm{~km}$.

\section{RESULT AND DISCUSSION}

The table-1 gives the calculated diameters of eight craters that we photographed through the telescope in the observatory and their values published in previous works [7]. The table also contains the difference between the calculated and published diameters of those craters. With the above values calculated in Table (1), we did the statistical analysis of the so measured data. Since, the measurement taken was not for same crater, so it was better to calculate mean and the standard error, of the difference between the measured and published 
Table: 1 Measured diameters of various craters and their formerly published diameters [7].

\begin{tabular}{llllll}
\hline Name & Latitude & Longitude & $\begin{array}{l}\text { Measured } \\
\text { diameter } \\
\text { (in km) }\end{array}$ & $\begin{array}{l}\text { Published } \\
\text { diameter }\end{array}$ & $\begin{array}{l}\text { Absolute } \\
\text { Difference } \\
(\mathrm{km})\end{array}$ \\
\hline Billy & 13.8 & 50.1 & 34.2615 & 45 & 10.7385 \\
Dopplemayer & 28.5 & 41.4 & 52.5770 & 64 & 11.423 \\
Gassendi & 17.5 & 39.9 & 78.2061 & 110 & 31.7939 \\
Hippalus & 28.8 & 30.2 & 37.1167 & 58 & 20.8833 \\
Mercator & 29.3 & 26.1 & 34.1241 & 47 & 12.8759 \\
Mersenius & 21.5 & 49.2 & 63.0196 & 84 & 20.9804 \\
Palmieri & 28.6 & 47.7 & 34.5972 & 40 & 5.4028 \\
Schickard & 44.4 & 54.6 & 226.8207 & 227 & 0.1793 \\
\hline
\end{tabular}

diameters. With the small sample size of $n=8$, the graph of published diameter versus the difference in measured and published diameter is shown in Fig-1.4 which clearly shows the random distribution of the data. It's because of the high range in the diameter of the largest and smallest crater.

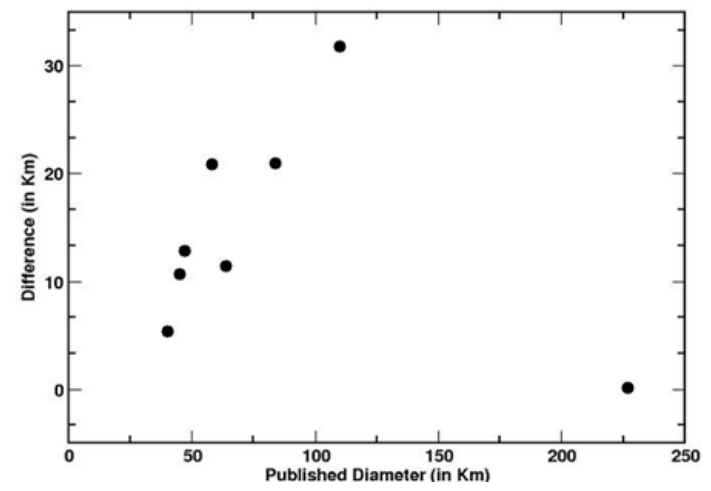

Figure: 1.4 Graph between the Published diameter and the absolute difference between calculated and published diameters.

The standard error of the difference between the published diameter and the measured diameter was found to be 1.8436. It is clear from the graph that the data is non-uniformly distributed. When we used the Chi square test to compare the data, the calculated value came as 30.8077 and the tabulated value at $10 \%$ level of significance is 12.017. From these data, we can say that though there is difference in the values of observed and calculated diameter, they do not differ signicantly. However, we didn't find any significant difference except for the Gassendi crater.

\section{CONCLUSION}

Among the many craters and mares on the moon's surface, the craters listed in table-1. were taken for study and the images of them were taken which are mostly around the Gassendi crater. The size ranges from 40 to $227 \mathrm{~km}$. The smallest crater in the list is Palmieri with diameter $40 \mathrm{~km}$ and the largest crater is Gassendi with diameter $227 \mathrm{~km}$ : Here, we came to know that the standard published value doesn't match with the value that we calculated and also that the shape of the craters are not similar to one another. From this, we can conclude that many factors are involved for the slight and the huge differences between the published and measured data. The shape of the crater, difference in the value of diameter for the surface and inner depth level and foreshortening are the major factors responsible for that. However, the published and measured values though seemed different do not differ significantly.

\section{ACKNOWLEDGEMENTS}

We Acknowledge B.P. Koirala Memorial, Planetarium Observatory and Science Museum Development Board, Singhadurbar, Kathmandu, Nepal. for providing local accomodation facility for several nights for observation in national observatery, Nagarkot. One of the authors (P. Prajuli) acknowledges the Board for providing financial support for this dissertation work in Astronomy .

\section{REFERENCES}

[1] www.nasa.gov/multimedia/imagegallery/image feature 25.html.

[2] Heiken, G. H., Vaniman D. T. and French, B. M. 1991. Lunar Sourcebook: A User's Guide to Moon, Cambridge University Press, Cambridge.

[3] Chaisson, E. and McMillan, S. 2004. Astronomy: A Beginner's Guide to the Universe, Pearson Education Inc., New Jersey.

[4] Meade LX200 Instruction Manual, Meade Instruments Corp 2006.

[5] http:// www.lunarrepublic/ atlas/index.shtml.

[6] Poudel, B. 2012. Determination of Size of some Lunar craters, MSc Thesis (TU).

[7] www.en.wikipedia.org/wiki/List of craters on the Moon. 